\title{
Contribuição a um projeto de reforma democrática do Estado*
}

\author{
Frederico Lustosa da Costa**
}

SumÁrio: 1. Introdução; 2. Pressupostos; 3. Crise: inflexão, ruptura e oportunidade; 4. Referências e aproximações à reforma democrática; 5. A peculiaridade brasileira; 6 . Contribuição ao delineamento da reforma democrática; 7. Flexibilização, universalização, isonomia e equanimidade; 8 . Gestão pública empreendedora; 9. Considerações finais.

Summary: 1. Introduction; 2. Assumption; 3. Crisis: inflection, rupture and opportunity; 4. References to and approximations of the democratic reform; 5. Brazilian specificity; 6. Contribution to the layout of the democratic reform; 7. Flexibilization, universalization, isonomy and equanimity; 8. Entrepreneurial public management; 9. Final remarks.

Palavras-chave: reforma democrática; administração e desenvolvimento; universalidade e participação.

KEY WORDs: democratic reform; management and development; universality and participation.

A crítica progressista à reforma do Estado dos anos 1990 tem se contentado em apontar as fragilidades políticas, teóricas, técnicas e operacionais do modelo predominante, sem conseguir construir uma alternativa que constitua, ao mesmo tempo, uma bandeira política sedutora (utopia), um corpo teórico consistente e um repertório de medidas viáveis. As propostas que se oferecem à discussão são, na maioria das vezes, pontuais e fragmentárias, centrando-se em aspectos valorativos da democracia, da participação e da inclusão social. A escassez de criatividade no campo progressista estimula os adeptos do mainstream a sustentarem a ideia de que não existem alternativas ao paradigma gerencialista. Este artigo apresenta de forma muito breve algumas dessas abordagens para traçar pelo menos parte do quadro de referências de modelo alternativo. Esses subsídios estão colocados tanto em pres-

\footnotetext{
* Artigo recebido em maio e aceito em dez. 2009.

** Professor da Fundação Getulio Vargas. Endereço: Praia de Botafogo, 190, sala 1506 _ CEP 22250-900, Rio de Janeiro, RJ, Brasil. e-mail: frederico.lustosa@fgv.br.
} 
supostos teóricos e interpretações mais abrangentes da crise do Estado quanto em análises de processos de mudança institucional, de transformação organizacional e de adoção de novas práticas de gestão pública. Para esse conjunto de ideias propostas e experiências orientadas para a reinvenção do Estado, adota-se aqui a designação da reforma democrática do Estado.

\section{A contribution to the democratic reform of the state project}

The progressive critique of state reform of the 1990s seems content with merely pointing out the political, theoretical, technical and operational frailties of the predominant model. This critique also fails to construct an alternative that is at once politically seductive (a utopia), theoretically consistent and capable of presenting repertoire of feasible measures. The proposals are mostly limited to certain points and are fragmented, focusing mainly on normative dimensions of democracy, participation, and social inclusion. The lack of creativity in the progressive field prompts mainstream claims that there is no alternative to the managerialist paradigm. This article provides a brief overview of some of the progressive approaches in order to outline at least partially the framework of an alternative model. This contribution is presented as theoretical assumptions and broader interpretations of the state crisis, as well as the analysis of institutional transformation processes, organizational transformation and the adoption of new practices in public administration. This set of proposed ideas and experiences oriented towards the reinvention of the state is called here the democratic reform of the state.

\section{Introdução}

Os meios de comunicação, já foi dito em outros contextos, cumprem uma função de agenda, dizendo-nos o que pensar, quer dizer, eles estabelecem os temas que devem ser discutidos pela sociedade. Alguns críticos lembram que, na verdade, eles cumprem uma função de não agenda (ou contra-agenda), dizendo-nos o que não pensar, excluindo os temas que não podem ser discutidos. Um terceiro ponto de vista assegura que as duas perspectivas se complementam. Ao estabelecermos uma agenda de discussão, estamos, de fato, censurando uma série de temas que não queremos debater (Lustosa da Costa, 2005:267).

É fácil reconhecer que o mesmo raciocínio pode ser aplicado a outros ramos do conhecimento. Com relação à reforma do Estado, a agenda que tem sido proposta pelos organismos internacionais exclui alguns temas fundamentais nunca discutidos em profundidade nos fóruns por eles animados. Pois as reformas realizadas nos últimos anos obedecem, sobretudo, ao imperativo orçamentário, ou seja, são feitas principalmente para reduzir gastos públicos. 
Balizadas por esse paradigma, elas se traduzem em três estratégias principais, a saber:

- a reforma patrimonial, que se faz principalmente através de processos de privatização e terceirização;

v a reforma fiscal (ou ajuste fiscal), voltada para a redução de despesas e, eventualmente, para o aumento das receitas;

$\checkmark$ a reforma gerencial, orientada para o aumento da eficiência dos serviços públicos.

Esse repertório deixa de lado uma série de questões relativas ao alcance da intervenção legítima do Estado, ao exercício dos direitos de cidadania, às formas de representação de interesses e de participação (política e cidadã) e ao caráter redistributivo do sistema tributário e das políticas públicas. Assim, o primeiro passo na constituição de uma agenda alternativa à reforma gerencialista é o preenchimento dessas lacunas. Para tanto, é necessário identificar e discutir os vários aspectos dos temas que estão excluídos da pauta da reforma do Estado que tem sido realizada no Brasil e no mundo.

Pois, em muitos casos, a crítica progressista ao padrão de reforma do Estado tem se contentado em apontar as fragilidades políticas, teóricas, técnicas e operacionais do modelo predominante, sem conseguir construir uma alternativa que constitua, ao mesmo tempo, uma bandeira política sedutora (utopia), um corpo teórico consistente e um repertório de medidas viáveis. As propostas que se oferecem à discussão são, na maioria das vezes, pontuais e fragmentárias, centrando-se em aspectos valorativos da democracia, da participação e da inclusão social.

A escassez de criatividade no campo progressista estimula os adeptos do mainstream a sustentarem a ideia de que não existem alternativas ao paradigma gerencialista. A new public management apresenta-se como o fim da história da administração pública. Economia de mercado, sufrágio universal, Estado regulador e nova gerência pública são partes complementares de um todo interdependente - a sociedade (autônoma e competitiva) do mundo globalizado.

Por outro lado, muitos dos defensores do Estado nacional e de um papel ativo na promoção do desenvolvimento e na redução das desigualdades, sobretudo no Brasil, têm adotado uma posição defensiva que, muitas vezes, rejeita a própria ideia de reforma. No plano político, setores corporativos organizados, ignorando manifestações mais agudas de crise fiscal, exercem pressão sobre o Legislativo e sobre o Executivo para que nada seja feito. Frequentemente, 
ouve-se o argumento ingênuo de que a crise fiscal decorre, em larga medida, da corrupção que atinge todos os setores do governo, bastando eliminá-la para que o Estado reencontre o equilíbrio fiscal e a boa governança. No Brasil, por exemplo, todas as estimativas mais alarmantes sobre desvios de recursos públicos chegam a somas anuais muito inferiores aos gastos com o pagamento de benefícios da Previdência Social em apenas um dia.

Outros ainda apresentam como contraponto à reforma do Estado as virtuosidades de experiências exitosas de desenvolvimento local integrado, participação cidadã, associativismo, microcrédito, inclusão digital, que têm feito proliferar fóruns, conselhos, associações, cooperativas e assembleias (Paula, 2005). Por maiores que sejam os resultados oferecidos por essas realizações coletivas de interesse local, elas têm reduzida capacidade de alterar o padrão de intervenção do Estado ou a essência das políticas distributivas. Ou seja, elas estão longe de constituir um processo de reforma do Estado.

É certo que as questões relativas à reforma do Estado suscitam reflexões mais consistentes, amparadas em conhecimentos produzidos nas diversas ciências sociais. Entretanto, a maior parte dessas contribuições não articula, de forma tão competente quanto o paradigma gerencialista, as dimensões econômica, político-social, institucional, organizacional e gerencial do problema. A próxima seção recupera de forma muito breve algumas dessas abordagens, para traçar pelo menos parte do quadro de referências de modelo alternativo. Esses subsídios estão colocados tanto em pressupostos teóricos e interpretações mais abrangentes da crise do Estado quanto em análises de processos de mudança institucional, de transformação organizacional e de adoção de novas práticas de gestão pública. A esse conjunto de ideias propostas e experiências orientadas para a reinvenção do Estado adota-se aqui a designação de reforma democrática do Estado.

\section{Pressupostos}

Antes de examinar alguns aspectos de uma contra-agenda, convém estabelecer alguns dos pressupostos que devem sustentar a discussão sobre a reforma democrática. Essas premissas são ditadas por uma série de "imperativos categóricos" compreendidos por uma antropologia, uma sociologia, uma ética e uma epistemologia específicas, já antecipadas na introdução.

Nenhuma discussão sobre reforma do Estado pode deixar de levar em conta as profundas transformações econômicas, sociais e políticas geradas pelas mudanças no padrão tecnológico que condicionam a formação da socie- 
dade pós-industrial. A emergência das tecnologias da informação e da comunicação (TIC) alterou significativamente a estrutura de produção de bens e serviços, com impacto substantivo nas formas de organização de trabalho, no regime de acumulação do capital e no modo de regulação das relações entre trabalho e capital (Lipietz, 1991:28). Ao mesmo tempo, a intensificação do comércio internacional, a abertura dos mercados e a livre circulação de capitais propiciaram o fenômeno da globalização econômica. Comunicações aceleradas, reestruturação produtiva e mundialização do capital ditaram uma nova ordem econômica internacional que reduz os graus de liberdade do Estado nacional. $\mathrm{O}$ acesso facilitado ao conhecimento e à informação e a interação mais intensa entre culturas favorecem a universalização de valores e a massificação de condutas. Na contracorrente, a afirmação de identidades referenciadas em grupos e regiões fortalecem os movimentos da sociedade civil e o localismo político e cultural. Vivemos no mundo da aceleração, em que a velocidade das comunicações muda os padrões de produção e consumo, as relações de troca, as formas de habitar e participar, destruindo fronteiras, volatilizando capitais, eliminando empregos e minando o poder de intervenção do Estado.

A reforma do Estado é, acima de tudo, uma questão política e, como tal, deve ser tratada (Nogueira, 1998 e 2004). Há uma tendência entre os reformadores gerencialistas a tratá-la como uma questão "técnica", que deve ser objeto de políticas pragmáticas. Segundo esse ponto de vista, os limites da intervenção do Estado no domínio econômico são ditados por critérios de eficiência; o equilíbrio fiscal de curto e longo prazos é um objetivo em si mesmo imposto pela racionalidade econômica; a política monetária e as atividades de regulação devem ser imunes à interferência nefasta dos interesses políticos; a gestão por resultados é a culminação do processo de racionalização da administração pública.

Ora, o alcance da intervenção legítima do Estado na vida econômica de uma nação é historicamente determinado; é fruto de opções sociais definidas politicamente mediante a deliberação coletiva estabelecida pelos mecanismos de representação. O equilíbrio fiscal e a política monetária em geral devem ser estabelecidos em função das prioridades nacionais, em consonância com os ciclos econômicos, o contexto internacional e a conjuntura. Políticas de regulação implementadas por agências autônomas podem ser afastadas das interferências políticas, mas nunca o são totalmente dos interesses que elas representam. A gestão pública deve estar orientada para a concepção de resultados esperados em decorrência do alcance de objetivos fixados por políticas públicas que, por definição, são políticas e públicas. A reforma do Estado, para qualquer direção que se encaminhe, interfere em aspectos distributivos 
e, portanto, em interesses de classes, grupos e indivíduos. Soluções técnicas, por mais engenhosas que sejam, são social e politicamente condicionadas. A eficácia dos instrumentos de gestão é limitada pelo contexto em que se dá sua utilização - ambiente, objetivos, recursos (humanos, materiais, financeiros, políticos e organizativos). Depende de onde, para que, quem e com que os utiliza. Existem problemas de gestão, mas existem também problemas econômicos, sociais, políticos e de muitas outras naturezas que devem ser resolvidos, politicamente, no seu campo próprio, com o uso de instrumentos de administração.

Não obstante as pretensões à formulação de teorias positivas, as discussões e soluções de problemas de natureza política têm, quase sempre, caráter normativo, embora seja cada vez mais difícil distinguir umas e outro, já que a racionalidade informa tanto a previsibilidade dos comportamentos quanto a inteligência dos modelos (Ferejohn e Pasquino, 2001). Afirmar a dimensão política da mudança institucional é atribuir-lhe uma dinâmica constitutiva cuja racionalidade é essencialmente política. A razão política equaciona valores, interesses, expectativas, barganhas e compromissos em torno de projetos de interesse coletivo. Nesse sentido, a teoria da reforma institucional é tão normativa quanto a própria reforma institucional, na medida em que supõe e define comportamentos consistentes com um fim determinado. Assim, nenhuma formulação sobre a reforma democrática estará isenta do viés normativo.

O contraponto à reforma gerencialista coloca em primeiro plano a questão democrática, sobretudo em países em que assimetrias sociais podem desfavorecer o exercício de direitos de cidadania. A reforma tem, portanto, o propósito de democratizar o Estado, mudando a natureza de suas relações com a sociedade, no sentido de assegurar a vigência da ordem igualitária. Há, nessa perspectiva, uma estreita relação entre democracia e cidadania, entre participação e garantias. No plano da existência civil, a mudança nas relações Estado-sociedade confere novos significados à segurança (individual e coletiva) e à repressão, à liberdade positiva, à inserção no mundo produtivo e às novas identidades, reduzindo disparidades de reconhecimento e valorização existencial por conta de situações de gênero, condição social, origem religiosa, local de moradia ou tipo de ocupação. No plano político, a mudança institucional orienta-se para a consolidação da poliarquia, a partir do pleno exercício de direito de cidadania, favorecendo o aumento da elegibilidade (Santos, 1998) e o exercício da democracia deliberativa (O’Donnell, 1991). No plano social, além do combate a todas as formas de exclusão e a redução das desigualdades na apropriação dos frutos do crescimento econômico, a democratização visa: à melhoria da qualidade de vida, à preservação do meio ambiente, ao acesso 
aos bens da cultura e a outros interesses difusos. Desse ponto de vista, a reforma do Estado passa por mudanças profundas nas relações entre Estado e sociedade e nos processos de afirmação de direitos civis, políticos e sociais, de competição e representação política e de transferência de rendas dentro da sociedade, vale dizer, de reformas no sistema político, no Poder Judiciário, na Previdência Social, no sistema tributário e no próprio aparelho do Estado.

A reforma democrática não pode deixar de considerar a complexidade do Estado em suas múltiplas manifestações. Representação da ordem social, expressão da soberania, instância instituinte, aparato normativo, aparelho repressivo, órgão alocativo e máquina burocrática, o Estado apresenta-se como um organismo polimorfo repartido entre os poderes da República e os níveis de governo. No caso brasileiro, que adota o presidencialismo como forma de governo e o federalismo como forma de Estado, são inúmeras as feições do Leviatã. Há os diversos corpos legislativos, o Poder Judiciário em suas diversas instâncias e o poder auxiliar do Ministério Público, as imensas estruturas do Executivo federal, os braços armados do dispositivo militar e do policiamento ostensivo, as agências reguladoras, a polícia judiciária, os tribunais de contas e as inúmeras estruturas das administrações estaduais e municipais. Convém, portanto, curvar-se ao imperativo da desglobalização enunciado por Rosanvallon (1990), que recomenda considerá-lo em suas diferentes manifestações. Esse procedimento evita sucumbir à tentação de conferir-lhe características monolíticas e uniformes ou, o que é pior, antropoformizá-lo, atribuindo-lhe preferências, volição e deliberação.

Pensada a partir dessas premissas, a reforma do Estado pode contemplar outras estratégias além da racionalização, entendida como o conjunto de medidas voltadas para o aumento da eficiência, por meio de redução de estruturas e cortes nos gastos públicos, e da desestatização, compreendida como o elenco de mudanças decorrentes da privatização de empresas e serviços públicos e da desregulamentação da vida econômica e social.

\section{Crise: inflexão, ruptura e oportunidade}

É comum a referência entre os estudiosos do management a um prodigioso ideograma chinês que expressa a ideia de crise, justapondo símbolos denotativos das noções de perigo e oportunidade. Ignorantes da escrita mandarim não precisam ir tão longe. Qualquer dicionário etimológico lembra que a palavra crise vem do latim crísis, que significa momento de decisão, de mudança súbita, acepção derivada do grego krísis que significa ação ou faculdade de 
distinguir, decisão. Os romanos também associavam a palavra a um momento decisivo de uma doença que, conforme a medicina ainda reconhece, pode evoluir para a cura ou para a morte. Assim, em nossos dois idiomas ancestrais, crise também tem o sentido de oportunidade e, mais do que isso, de momento de decisão, de porta aberta para a ação.

Esse breve preâmbulo tem o singelo propósito de introduzir a ideia da crise do Estado na sua acepção mais simples, de mudança súbita num dado estado ou situação. Essa perspectiva tem a vantagem de evitar a definição do problema da mudança institucional como a falta de determinados atributos ou características que, quando assim estipulados, fazem com que traga implícita uma solução que nem sempre é a melhor possível.

A interpretação da crise do Estado, do ponto de vista da abordagem gerencialista, foi analisada anteriormente. Conviria agora repertoriar as principais visões alternativas ao modelo de crise fiscal. Esse exercício, entretanto, já foi realizado inúmeras vezes em trabalhos originários dos diversos campos das ciências sociais. Uma síntese das interpretações da crise do Estado percebidas como crise de governabilidade é apresentada no Dicionário de Política de Norberto Bobbio, Nicola Matteocci e Gianfanco Pasquino (1995). No verbete sobre governabilidade, Pasquino identifica três tipos de explicação da não governabilidade ou da crise de governabilidade:

v como problema de natureza política decorrente do excesso de demandas e da diminuição da autoridade (crise de democracia);

- como produto de uma sobrecarga de problemas a que o Estado responde com a ampliação dos seus serviços, aumentando suas despesas (crise fiscal do Estado);

- como produto da contradição entre as necessidades de garantir a acumulação e manter a legitimação, gerando problemas de gestão e de legitimação (crise de racionalidade).

A primeira dessas interpretações está associada ao nome de Samuel Huntington e é francamente conservadora. O essencial do seu argumento diz que o desenvolvimento da democracia passa pelo aumento da participação e pela institucionalização dos processos e das organizações políticas. O problema é que essa vitalidade, muitas vezes, é acompanhada pela diminuição da autoridade. Num momento que se requer mais e mais intervenção do Estado, a crise de autoridade reduz a confiança dos cidadãos "nas instituições do governo e [causa] a queda de credibilidade dos governantes", provocando "uma diminuição de sua capacidade para enfrentar os problemas, dentro de um 
círculo vicioso que pode ser definido como a espiral da não governabilidade" (Bobbio et al., 1995:551).

As duas últimas interpretações ainda são tributárias da herança marxista. A da crise fiscal do Estado está associada, sobretudo, ao nome de James O'Connor e é uma manifestação da inexorável crise do capitalismo. Nesse caso, ela decorre do descompasso entre o crescimento do produto nacional bruto e a elevação dos custos dos programas públicos e das demandas dos trabalhadores. Esse desequilíbrio tem impacto sobre a eficácia do governo e sobre o consenso social que o legitima. Trata-se da contradição fundamental entre a necessidade de criar condições para uma rentável acumulação do capital e, ao mesmo tempo, garantir condições de harmonia social. Na tradição marxista não há solução à vista, pois o problema se resolve por si mesmo com a queda do Estado capitalista.

Note-se que os argumentos da versão marxista da crise fiscal não estão muito longe da versão conservadora da crise de democracia. Em ambos os casos há excesso de demandas, pelo menos no sentido de que elas ultrapassam as condições de equilíbrio do sistema. $\mathrm{O}$ argumento também é semelhante ao diagnóstico da crise fiscal do Consenso de Washington e do reformismo gerencialista. Nesse caso, os reformadores têm pronto o seu repertório de medidas para a superação da crise - reduzir significativamente as atividades do governo, reduzir as expectativas dos grupos sociais, aumentar os recursos e os ingressos à disposição do Estado (inclusive com a reforma patrimonial) e, finalmente, reorganizar e simplificar as instituições governamentais.

Mesmo nesse campo não há mais unanimidade com relação à eficácia de longo prazo das medidas orientadas para a busca da estabilização econômica. Stiglitz (2002) lembra que as recomendações do Consenso de Washington por sua simplicidade e foco no essencial são bastante eficazes no combate à inflação, mas podem ser incompletas e, por vezes, equivocadas como estratégia de crescimento de longo prazo. Segundo seu ponto de vista, a liberalização comercial e a privatização não são fins em si mesmo. Elas devem contribuir para aumentar a concorrência e serem complementadas com reformas financeiras, instrumentos de regulação e políticas orientadas para a construção de capital humano, a transferência de tecnologias e a efetividade da ação pública. Tratase de ampliar os objetivos do desenvolvimento (com equidade, participação e democracia), constituindo um mix com a melhoria da educação, a proteção ao meio ambiente, o investimento em tecnologia e a ampliação dos canais de participação.

A crise de racionalidade está ligada ao nome Jürgen Habermas e também aceita alguns dos pressupostos das abordagens anteriores. Seria temerá- 
rio tentar resumir num parágrafo o argumento de Habermas, mas é suficiente adiantar que a crise de racionalidade do Estado capitalista decorre da contradição entre a necessidade de proteger a propriedade privada (e a acumulação do capital) e, ao mesmo tempo, cumprir funções sociais (de caráter redistributivo). É a conjugação de uma crise de input e de uma crise de output. Segundo Habermas citado por Bobbio (1995:548):

as crises de output têm a forma da crise de racionalidade: o sistema administrativo não consegue compatibilizar, nem agilizar eficientemente, os imperativos de controle que lhe chegam do sistema econômico. As crises de input têm a forma das crises de legitimação: o sistema legitimador não consegue preservar o nível necessário de lealdade da massa. Impulsionando assim os imperativos de controle do sistema econômico que ele assumiu.

Uma quarta interpretação da crise do Estado pode ser creditada à Escola de Regulação francesa, também herdeira da tradição marxista. Os regulacionistas franceses realizaram uma simplificação e atualização de alguns dos conceitos fundamentais do marxismo para analisar a crise vivida pela economia capitalista a partir do final dos anos 1960. Nessa teorização, o estágio avançado do modo de produção capitalista é descrito como "modelo de desenvolvimento", o fordismo, constituído basicamente de:

v um modelo de organização do trabalho (ou "paradigma tecnológico"; ou "modelo de industrialização"), referindo-se aos princípios gerais de organização do trabalho no interior das empresas e de divisão de trabalho entre as empresas;

v um regime de acumulação, que contempla as leis macroeconômicas das condições da produção (produtividade do trabalho, grau de mecanização, importância relativa dos diferentes ramos) e das condições de uso da produção;

v um modo de regulação que estabelece os mecanismos de ajuste dos comportamentos contraditórios dos indivíduos aos princípios coletivos do regime de acumulação, englobando as regras de mercado, a legislação social, a moeda, as redes financeiras.

O fordismo é o modelo de desenvolvimento do capitalismo avançado apoiado no taylorismo e na mecanização favorável à produção em massa (organização do trabalho) que permitiu elevar os ganhos de produtividade, estabilizar taxas de lucros e aumentar o poder aquisitivo dos trabalhadores (regi- 
me de acumulação) e pactuar melhores condições de reprodução da força de trabalho e sistemas de previdência para assegurar renda às pessoas impedidas de trabalhar (modo de regulação). Esse sistema entrou em crise, com a redução dos ganhos de produtividade das economias industriais sem diminuição nas altas salariais, reduzindo as taxas de lucro. A necessidade de aumento da produtividade, com a adoção de novos sistemas de produção e práticas gerenciais, gerou desemprego e redução da capacidade de pressão dos sindicatos, minando o poder dos trabalhadores e as bases de financiamento do welfare state.

Muitas das análises precedentes se revelaram equivocadas nas suas previsões. Mais uma vez, a economia capitalista deu mostras de sua capacidade de renovação e adaptação, entrando em um novo ciclo de crescimento, apoiado em novas tecnologias e novos mercados. Alteraram-se as bases de organização da produção (pós-fordismo) e do regime de acumulação. Resta em aberto a constituição de um novo modo de regulação. Entretanto, essas contribuições, apesar da sua reduzida capacidade de previsão, têm virtudes descritivas e analíticas importantes. Servem pelo menos para ampliar o foco de análise dos problemas e chamar a atenção para a dimensão política da crise.

Em resumo, a crise do Estado é, ao mesmo tempo, uma crise de regulação, uma crise de governabilidade e uma crise de democracia, que se manifesta:

- na perda de sua capacidade de regular as relações entre economia e sociedade, as transferências de renda dentro da sociedade e os conflitos distributivos a elas inerentes;

v na redução dos seus graus de liberdade para formular políticas públicas e coordenar decisões econômicas; e

- na reconfiguração da cidadania, pela perda de centralidade do trabalho como fundamento das identidades individuais e coletivas.

Essa crise, evidentemente, tem impactos nas finanças públicas e na eficiência gerencial dos serviços oferecidos pelo Estado, fomentando também a crise fiscal e a crise de governança.

\section{Referências e aproximações à reforma democrática}

Desde que começou a se consolidar o paradigma da reforma gerencialista, no início dos anos 1980, surgiram contestações do lado do campo progressista, nutridas pelas referências dominantes na ciência política dos anos 1960 e 
1970 - as abordagens pluralista e marxista. Comprometidas com o consenso social-democrata, essas contribuições, em sua maioria, não se apresentavam como respostas a problemas emergentes, e sim como críticas aos projetos de reforma que começavam a se constituir no chamado "pensamento único" sobre o tema. Países de larga tradição na produção de conhecimento em ciências sociais, como a França e a Alemanha, recuaram no cumprimento da agenda social-democrata e se mantiveram paralisados na formulação de propostas alternativas. Intelectuais da importância de Pierre Bourdieu e Alain Touraine, na França, e Jürgen Habermas e Klaus Offe, na Alemanha, não obstante a percuciência de suas análises das transformações do mundo globalizado, não foram capazes de formular um quadro teórico capaz de contrapor-se em toda linha ao paradigma neoliberal. Mesmo pensadores mais próximos ao tema da crise do welfare state como Pierre Rosanvallon e Robert Castel não oferecem respostas de caráter programático. Assim, uma agenda para a reforma democrática teria que ser construída a partir de proposições esparsas encontradas nos trabalhos desses e de outros autores.

Frequentemente, são citados como pontos de referência para a constituição do programa da reforma democrática:

v diversos aspectos da obra de Habermas, a começar pela sua reflexão sobre os processos de transformação do espaço público e sua análise da crise de legitimação do capitalismo, já referida, que estão na base da sua teoria da ação comunicativa e do modelo de democracia deliberativa (Bento, 2003; Tenório, 2004; Paula, 2005);

v as análises de Klaus Offe (1984) sobre as transformações do mundo do trabalho e os problemas estruturais do Estado capitalista, em particular aqueles relacionados às novas tensões entre administração e política, decorrentes da substantivação das decisões do nível burocrático (Martins, 1995);

v a extensa reflexão de Manuel Castells (1998) sobre as transformações da sociedade contemporânea que tem como referência principal a noção de rede, utilizada para caracterizar também o Estado-rede, mais flexível, mais aberto à avaliação externa, à participação cidadã e ao controle social, mais orientada para a função de coordenação;

v as análises de Pierre Rosanvallon $(1981,1995)$ sobre a crise do Estadoprevidência, a emergência de novas desigualdades e a nova questão social, em particular as propostas de refundação da solidariedade e da revisão das relações entre direitos, trabalho e seguridade social (Fitoussi e Rosanvallon, 1996); 
- as discussões sobre gestão social, entendida, ao mesmo tempo, como uma abordagem específica, um campo de intervenção e um conjunto de instrumentos orientado para novas formas de ação pública nos domínios governamental, não governamental e privado (Lustosa da Costa, 1998; Tenório, 1998; Kliksberg, 1996, 1999, 2001);

v o debate sobre participação cidadã na gestão pública, sistematizado por Cunill Grau (1991, 2005) e Kliksberg (2005), envolvendo as diversas formas de ampliar a inserção da cidadania no planejamento, na deliberação, na administração, na fiscalização e no controle das políticas públicas, incluindo o referendo, o plebiscito, a iniciativa legislativa, os fóruns temáticos, os conselhos gestores de políticas públicas, o orçamento participativo e a ação das organizações não-governamentais (Fleury, 2001; Bento, 2003; Paula, 2005).

\section{A peculiaridade brasileira}

Conforme apresentado, a reforma gerencialista começou no Brasil, de forma intuitiva e errática, em 1990, quando da posse do governo Fernando Collor de Mello, que realizou uma série de remanejamentos estruturais, intensificou o programa de privatizações e pretendeu implementar reformas constitucionais de cunho liberalizante. Observe-se que tal governo teve início apenas 17 meses após a promulgação da Constituição de 1988, que consagrou vários princípios que estavam em causa nos projetos governamentais - monopólios estatais, reserva de mercado, universalização de serviços sociais e vinculação de receitas. Desde então, com maior ou menor retardo, todas as reformas que iam de encontro a esses princípios - abertura comercial, flexibilizações de monopólios, privatizações - foram feitas.

Em muitos sentidos pode-se dizer que a Constituição de 1988 realizou uma ampla reforma no Estado brasileiro. Ela introduziu novos princípios de organização do Estado, requalificou direitos de cidadania, redefiniu a matriz de extração e alocação de recursos da sociedade, fixou os limites da intervenção do Estado, reorganizou alguns dos seus serviços e inseriu novos instrumentos de política pública, sobretudo na área social. Nesse último aspecto, as mudanças foram muito significativas.

Com efeito, a Carta de 1988 criou o sistema de seguridade social, reunindo sob um mesmo guarda-chuva institucional e financeiro a Previdência Social, a assistência à saúde e a assistência social. Subsistemas presididos por lógicas diferentes, "a saúde pela incapacidade, a previdência pela condição 
de trabalho e a assistência pela necessidade" (Fleury, 2006:54), também se orientam por princípios diversos, "sendo a universalidade da cobertura e do atendimento o eixo do Sistema Único de Saúde, a uniformidade e equivalência dos benefícios e sua irredutibilidade a base da reforma da Previdência Social, e a seletividade e distributividade o princípio orientador da política de assistência social" (Fleury, 2006:54). Dos três componentes da seguridade social, o Sistema Único de Saúde é o mais organicamente estruturado, a partir de uma complexa rede de relações entre esferas de governo, bases de financiamento e serviços públicos e privados. Além de suas virtudes intrínsecas, decorrentes da aplicação dos princípios da universalidade (atende a todos os cidadãos), da integralidade (oferece todos os tipos de procedimentos, dos mais simples aos mais complexos, inclusive órtese e prótese), da hierarquização (da atenção primária aos procedimentos de alta complexidade; do ambulatório ao hospital de referência) e regionalização (aproximando beneficiários e serviços de assistência), o Sistema Único de Saúde (SUS) é uma experiência muito bem-sucedida de descentralização. Ele envolveu os três níveis de governo na gestão e no financiamento de suas atividades e transferiu as maiores responsabilidades para os municípios, nível de governo mais próximo dos cidadãos beneficiários. Isso vem sendo feito de forma gradual, de acordo com a capacidade de cada município. Em cada nível de governo, há conselhos (nacional, estaduais e municipais) de saúde que incluem representantes do setor público, das corporações, do saber médico e da sociedade organizada. Há uma interlocução entre os municípios e os conselhos estaduais de secretários municipais de saúde e no Conselho Nacional de Secretários Municipais de Saúde e, entre estados, no Conselho Nacional de Secretários Estaduais de Saúde. A cada quatro anos, toda essa comunidade de dirigentes públicos, organizações sociais, corporações e militantes do movimento sanitarista se reúnem nas conferências nacionais de saúde (Alcântara e Lustosa da Costa, 1991).

A mesma lógica institucional e organizativa foi levada para a área de assistência social com a promulgação da Lei Orgânica da Assistência Social (Loas). Mas falta a esse sistema a organização política dos quadros da saúde (constituída ao longo de uma história de lutas de três décadas) e a base de financiamento repartida entre as três esferas de governo. A assistência social não logrou constituir-se num verdadeiro sistema integrando as esferas de governo e os instrumentos de intervenção. De forma paralela aos dispositivos constitucionais, os dois últimos governos criaram programas de transferência de renda e atenção focalizada a grupos marginalizados (Fleury, 2006:62-64).

No que diz respeito à Previdência Social, desde 1988, quando houve os últimos avanços na direção da ampliação da cobertura, incluindo empregados 
domésticos, e da fixação do valor do menor benefício em um salário mínimo, todas as reformas realizadas têm sido orientadas na direção do equilíbrio atuarial e financeiro. As principais mudanças foram realizadas através de reformas constitucionais em 1998, 2003 e 2005, que vincularam os benefícios às contribuições, elevaram a idade mínima para a aposentadoria e reduziram os privilégios dos servidores públicos.

Além da seguridade social a área de educação também sofreu reformas importantes no sentido do fortalecimento de sua base de financiamento e da descentralização. O que contribuiu para a quase universalização do acesso ao ensino fundamental das crianças brasileiras da faixa etária de 7 a 14 anos. Tradicionalmente, as competências na área de educação estão divididas entre os três níveis de governo, cabendo a cada um deles responsabilizar-se prioritariamente por um nível escolar. À União cabe o ensino superior, aos estados o ensino médio e aos municípios o ensino fundamental. Embora os estados tenham suas universidades e muitas vezes se ocupem do ensino fundamental e os municípios tenham suas escolas de ensino médio e alguns cheguem a criar faculdades isoladas. Por meio da Emenda Constitucional no 14, de 1996, foi criado o Fundo de Manutenção e Desenvolvimento e Valorização do magistério (Fundef), que vinculou receitas e as redistribuiu entre estados e municípios de acordo com o número de vagas oferecidas no ensino fundamental. A criação do Fundef e a implementação da Lei de Diretrizes e Bases da Educação Nacional promoveram a capacitação de professores, o aumento da sua remuneração, a ampliação do número de vagas e o fortalecimento da gestão escolar, com o apoio das associações de pais e mestres e das caixas escolares (pequenos fundos de custeio).

A maior parte dessas iniciativas constituiu exemplos de uma espécie de contrarreforma que se realizou no Brasil durante os anos 1990. De fato, essas medidas, além de pequenas mudanças no Poder Judiciário, como a criação dos juizados especiais (pequenas causas), e com o fortalecimento das defensorias públicas, produziram mudanças qualitativas nas relações entre o Estado e a sociedade, produzindo impactos importantes no exercício de direitos individuais e coletivos.

\section{Contribuição ao delineamento da reforma democrática}

Todas essas referências precedentes e outras indicadas nas demais seções deste artigo contribuem para a formação da agenda democrática do Estado, pois veiculam os temas excluídos do debate que se realizou nos últimos anos em 
torno do modelo gerencialista. É verdade que alguns desses pontos são mencionados de forma direta ou indireta na literatura sobre reforma do Estado. De forma direta, são sugeridos, muitas vezes, como aspectos principais de uma transformação política e institucional que, embora importante e efetiva, não chegam a constituir uma reforma do Estado. De forma indireta, eles aparecem como dados secundários da agenda principal, como aspectos funcionais à mudança gerencialista ou como externalidade do processo.

O propósito desta seção é articular esses temas num quadro de referência da reforma do Estado e situá-los como respostas a alguns desafios impostos pelas condições sociais e políticas que ensejam as representações do patrimonialismo, do mandonismo, do personalismo e do clientelismo. Assim, a reforma do Estado ganha aquela amplitude reivindicada aqui, transcendendo os aspectos fiscais, patrimoniais e gerenciais para incluir dimensões relacionadas à mudança social, à democracia e à cidadania. A agenda da reforma democrática inclui, pelo menos, propostas de mudanças no sistema político, no arcabouço institucional e no aparelho de Estado, orientadas para o desenvolvimento, a democratização, a descentralização, a regionalização, a integração das ações do governo, a flexibilização (com garantia de universalidade, isonomia e equanimidade) e a gestão pública empreendedora.

\section{Desenvolvimento}

A reforma do Estado não é um objetivo em si. Mesmo da perspectiva do paradigma gerencialista, ela visa sanear as finanças públicas e aumentar a eficiência da administração com vistas ao equilíbrio fiscal e à estabilidade econômica, condições fundamentais ao crescimento de longo prazo. Esse objetivo é amplamente aceito pela sociedade, embora não haja consenso sobre a eficácia de alguns remédios propostos pelos monetaristas, nem sobre a extensão de seus efeitos colaterais. O combate à inflação, acima de qualquer outro objetivo, não é garantia de crescimento econômico, nem a médio nem a longo prazos (Stiglitz, 1998). Além do mais, crescimento não é desenvolvimento. Mas de que desenvolvimento se trata?

Para fugir à tentação de abrir uma discussão muita larga sobre os conceitos e as estratégias de desenvolvimento, convém buscar na literatura aqueles consensos mínimos que constituem o núcleo das representações coletivas e atravessar espaços geográficos, temporais e sociais. Para além da hierarquização das classes sociais, da diversidade cultural, das diferenças de gênero, do 
hiato entre gerações, é possível supor que os cidadãos preferem uma situação (de desenvolvimento) em que de acordo com Harrison (2002:28):

$\checkmark$ a vida é melhor do que a morte;

v a saúde é melhor do que a doença;

$\checkmark$ a liberdade é melhor do que a escravidão;

$\checkmark$ a prosperidade é melhor do que a pobreza;

v a educação é melhor do que a ignorância;

$\checkmark$ a justiça é melhor do que a injustiça.

Para além do progresso material, quer dizer, do crescimento da renda dos indivíduos, Amartya Sen (2000) define desenvolvimento como o aumento da capacidade de os indivíduos fazerem escolhas. Assim, a liberdade individual é essencial para se alcançar melhor qualidade de vida. E a liberdade, para Sen, tem um sentido positivo que vai muito além da ausência de restrições. É a possibilidade física, material e intelectual de ir e vir, sonhar, fazer e deixar de fazer e viver. É a plausibilidade das opções e a factibilidade de suas consequências. É a conquista de capacidades, qualificações e prerrogativas para o movimento, a troca, o prazer e a valorização simbólica da existência. Assim, a obtenção dessas capacidades está condicionada à eliminação da pobreza e à garantia do atendimento das necessidades essenciais dos indivíduos.

Sem relativizar os fatores materiais e os indicadores econômicos, essa nova concepção de desenvolvimento insiste na necessidade de ampliação do horizonte social e cultural da vida das pessoas. As bases materiais do desenvolvimento humano são fundamentais, mas devem ser consideradas um meio e não um fim em si mesmas. O simples crescimento econômico não assegura desenvolvimento social e cultural. A educação, por exemplo, é um dos meios incontornáveis para que se possa hoje alcançar paz, segurança, justiça, liberdade e bem-estar. Educação é inclusão. Inclusão é liberdade. Liberdade é desenvolvimento.

Uma reforma do Estado orientada para o desenvolvimento passa evidentemente pelo equilíbrio fiscal de longo prazo, o que implica rever a lógica de financiamento, inclusive do sistema previdenciário. Passa também pelo estabelecimento dos próprios objetivos do desenvolvimento. Nos dois sentidos, ela contempla mudanças institucionais orientadas para:

v a revisão do sistema tributário para assegurar maior justiça fiscal, caráter redistributivo, estímulo à poupança, ao investimento e à produção, equilíbrio e cooperação federativas e fortalecimento das economias locais; 
- a recuperação da capacidade de coordenação de decisões econômicas, junto ao setor privado, levando em conta considerações relativas à redução das desigualdades sociais, à ocupação do território, à capacitação tecnológica e ao meio ambiente;

v a efetividade das políticas públicas pela relevância e abrangência de seus objetivos, abertura e transparência de seus processos de tomada de decisão, eficácia dos resultados e avaliação positiva de seus impactos.

O grande desafio da reforma democrática para o desenvolvimento é político. Trata-se de realizar um grande esforço de concertação, com vistas a construir consensos em torno dos objetivos e da morfologia do novo Estado social e pactuar as necessárias transferências de renda dentro da economia e entre a economia e a sociedade. O principal problema está relacionado com o financiamento do gasto público, em particular da seguridade social que, no Brasil, contempla o seguro social, a assistência à saúde e a assistência social. A antiga lógica contributiva, baseada no regime de repartição simples e na solidariedade de gerações, tornou-se inviável, porque as taxas de desemprego aumentaram, a esperança de vida cresceu e o ingresso no mercado de trabalho se dá mais tarde. Quer dizer, embora os indivíduos contribuam por mais tempo, recebem benefícios superiores às suas contribuições por períodos cada vez mais longos. Somente uma política de trabalho forçado e mortalidade compulsória, de sorte que as pessoas se reformem em idade próxima ao óbito, permitiria devolver o equilíbrio a um sistema baseado em tal lógica. Por outro lado, o modelo de crescimento econômico vigente ainda é capaz de financiar parcialmente o sistema de seguro desemprego, levando à manutenção de um Estado social que prefere indenizar desempregados a pagar trabalhadores. A refundação do sistema de seguridade social passa pela repactuação de sua base de financiamento, vale dizer, das transferências de renda dentro da sociedade. $\mathrm{O}$ novo modelo de custeio não pode ter vinculação direta à folha de salários, mas depende da participação do segurado.

\section{Democratização}

A democratização do Estado diz respeito a todas as medidas voltadas para a mudança nas suas relações com a sociedade, no sentido de afirmar-se como sustentáculo da ordem igualitária e fiador de direitos de cidadania. Essa mudança deve levar em conta a própria reconfiguração da cidadania, a partir da transformação das identidades individuais e coletivas. O emprego formal (e, 
quem sabe, o próprio trabalho) perde centralidade como fator constituinte da identidade individual. Do ponto de vista coletivo, as identidades se constituem, ao mesmo tempo, pelas referências globais e pelas raízes locais. Em relação à vida urbana, questões relacionadas à mobilidade e à temporalidade são fundamentais para definir a qualidade de vida e a essência dos direitos a ela inerentes.

É verdade que é muito difícil atuar nessa dimensão, porque ela depende de reformas institucionais que encontram fortes resistências em setores oligárquicos da representação política. Requer também a superação da cultura política de acomodação ainda prevalecente em vastos contingentes da população, tornando-a mais imune ao clientelismo, ao mandonismo e à oligarquização e mais aberta à competição e à participação. Implica intervenções no sistema político, no Poder Judiciário e no aparelho repressivo do Estado, além de melhorias nos serviços públicos em geral, contemplando reformas orientadas para:

- fortalecer o sistema político, preservando suas características de proporcionalidade dos votos e representação de minorias, no sentido de aumentar a elegibilidade dos cidadãos dotados de menores recursos políticos (e financeiros) e a competitividade entre partidos, sobretudo no nível local;

- assegurar acesso à Justiça, ágil e barata, a todos os cidadãos, com a ampliação do número e do escopo de ação dos juizados especiais de pequenas causas, com multiplicação das defensorias públicas e com a revisão dos processos de forma a lhes dar maior celeridade;

- reaparelhar o dispositivo policial, com vistas a aumentar a eficácia do combate à criminalidade e a segurança da população, evitando quaisquer formas de discriminação dos mais pobres quando do uso da força e de outros meios de repressão;

- melhorar a eficiência e a qualidade dos serviços de atendimento ao cidadão, reduzindo o tempo de espera, melhorando o conforto nas repartições públicas, facilitando o acesso por telefone e internet e agilizando o processamento das demandas. Essas melhorias devem se dirigir não só para as atividades que exigem o cumprimento de obrigações, mas também para as funções relacionadas com a entrega de bens e serviços à população.

- No caso brasileiro, ainda é preciso buscar formas de ampliar a oferta de serviços públicos, reduzindo o déficit e os custos impostos à população pelas filas, os atrasos e o mau atendimento. A administração pública deve atender a todos igualmente, deve ser universal na prestação e equânime no atendi- 
mento. Como ela não pode fazê-lo, acaba por cobrar preços não monetários para reprimir a demanda. Aqueles que não podem pagar esses preços, como o tempo perdido nas filas, acabam por desistir do serviço. Democratizar o Estado é universalizar o acesso e abolir esses preços.

A democratização também inclui as medidas orientadas para a ampliação dos espaços de participação. Nos últimos 20 anos, o Brasil tem vivenciado inúmeras experiências de participação, umas de natureza localizada, outras de aplicação geral. Os anos 1970 e 1980 foram repletos de experiências similares em vários municípios brasileiros, que introduziram formas variadas de participação da população na gestão do poder local. A Constituição de 1988 consagrou os instrumentos de democracia direta - o plebiscito, o referendo e a iniciativa popular de leis. Também determinou a criação de conselhos para a gestão de políticas públicas, sobretudo nas áreas de saúde, assistência social e educação. A partir dos anos 1990 os fóruns de desenvolvimento local e os temáticos têm se multiplicado, reunindo setores representativos das comunidades para construir e deliberar sobre projetos de interesse coletivo (Bento, 2003:320-350; Paula, 2005:162-168).

Deve-se buscar também novas formas de comunicação biunívoca no sentido de que as ações tenham um sujeito universalmente reconhecido e um mesmo significado para o governo e para a sociedade. Ou seja, a comunicação eficaz cria condições para que a administração perceba as demandas comunitárias e se faça entender pela comunidade, de sorte a adotar, em proveito da quantidade e qualidade dos serviços públicos oferecidos, a perspectiva das clientelas. Ao mesmo tempo, também favorece a humanização das relações entre pessoas (que estão dos dois lados do guichê) e a responsabilização dos agentes do poder público.

Todas essas formas de participação têm sido incorporadas às instituições e às práticas da administração pública brasileira. A ampliação desses espaços de participação deve ser feita com a consciência de seus limites e possibilidades. A participação é um valor em si mesmo, intrínseco à cidadania ativa e funcional ao sucesso de projetos de interesse coletivo. Mas não é uma panaceia para todos os males da gestão pública. Ela tem limites relacionados ao custo, em termos de tempo e recursos, das decisões; pode ser penalizada por assimetrias de poder dos espaços de deliberação coletiva; está sujeita a ser manipulada pelo saber técnico localizado em corporações específicas; e obedece a estímulos (Olson, 1999) e aos ciclos de interesse (e desinteresse) por assuntos públicos (Hirschmann, 1979) que supostamente afetam os cidadãos (Lustosa da Costa e Cunha, 2004, 2005). 


\section{Descentralização}

As vantagens da descentralização e da municipalização, do planejamento e da gestão de serviços públicos de consumo individual e coletivo, mediante grande interação com a clientela, são bastante conhecidas. Sua prática efetiva aproxima as decisões (de interesse coletivo) das ações, democratizando a gestão, na medida em que facilita a participação, legitima o planejamento e permite um maior controle por parte da comunidade. Ao mesmo tempo, a administração descentralizada pode desburocratizar o processamento de demandas sociais, já que agiliza a ação local, sem a desnecessária interferência de instâncias não interessadas no produto (Alcântara e Lustosa, 1991:9).

Como estratégia de reforma democrática, a descentralização deve ser considerada em suas duas dimensões - intergovernamental e administrativa. No primeiro caso, diz respeito à transferência de encargos e recursos para esferas de governo mais próximas ao cidadão, adotando-se o princípio da subsidiariedade - tudo que o Estado puder fazer a União não fará; tudo que o município puder fazer o estado não fará. No segundo caso, corresponde à desconcentração do poder dentro das organizações públicas, por meio do fortalecimento de unidades executoras dos serviços - escolas, hospitais, ambulatórios, creches, delegacias etc. Trata-se de aproximar as decisões das ações e dos fatos que as ensejam e adotar modelos organizacionais de alta capilaridade, capazes de assegurar um elevado grau de resolubilidade de demandas nas unidades operacionais, valendo-se de parcerias e alianças.

Como no caso da participação, a descentralização não pode ser vista como solução para todos os problemas, uma vez que ela pode gerar dificuldades de coordenação, suscitar conflitos de competência, aumentar custos e dificultar a solução de problemas de natureza supralocal. Por outro lado, a descentralização, se não acompanhada dos necessários instrumentos de controle social, pode fortalecer as estruturas do mandonismo oligárquico e tornar os serviços públicos mais suscetíveis a influências político-partidárias negativas.

\section{Regionalização}

A regionalização visa promover o desenvolvimento equilibrado e sustentável e assegurar a presença do poder público em todas as regiões de um país. É complementar à descentralização. Também consiste num processo democrático de aumento do especo público e da ordem igualitária, na medida em que se estende a presença do Estado (imperium) a todas as regiões do país e fa- 
vorece uma distribuição mais equânime dos recursos públicos. Essa forma de organização impõe o planejamento (e o orçamento) regional e a construção de diferentes matrizes de regionalização.

A regionalização implica fortalecer as unidades locais e regionais do Poder Executivo, permitindo que o governo reaja com maior rapidez às demandas diversificadas da população pernambucana e na organização de um sistema de planejamento estratégico que tenha como eixo a promoção do desenvolvimento regional integrado e sustentável. A regionalização precisa estar vinculada ainda à desconcentração da ação de governo, à cooperação intergovernamental e à parceria entre o Estado e a sociedade civil.

Iniciativas nesse sentido têm sido adotadas por vários países e governos estaduais no Brasil, ${ }^{1}$ que estão regionalizando a estrutura do Poder Executivo. A matriz de regionalização deve ser definida a partir de um estudo mais rigoroso das características de cada região, o Estado começa a colher os frutos dessa experiência. O Plano Plurianual de Investimentos (PPA) é um instrumento importante para resgatar o planejamento regional, na medida em que pode estruturar os gastos por regiões (ou estruturantes de desenvolvimento, a partir das bases logísticas existentes em cada região).

\section{Integração}

O modelo burocrático, ainda prevalente na administração pública, com seu foco na especialização funcional e no formalismo dos controles, não é mais capaz de articular a ação governamental em um ambiente de mudanças aceleradas e descontínuas. Seu rigoroso formalismo, sua impessoalidade cega ao foco das políticas públicas e à singularidade do caso individual e sua baixa tolerância a elevados níveis de incerteza reduziram em muito sua capacidade de oferecer respostas tempestivas e adequadas aos interesses diversificados da cidadania republicana do século XXI. Seu poder analítico e normativo é hoje claramente insuficiente para planejar, agenciar, operacionalizar e avaliar os esforços coletivos em favor do bem comum.

\footnotetext{
${ }^{1}$ A partir de 1999, o governo do estado do Maranhão desenvolveu uma experiência de reforma administrativa que privilegiou a regionalização da ação de governo. O estado foi dividido em 18 regiões para as quais foram criadas 18 gerências regionais, com atribuições de superintender todas as atividades do governo estadual nas suas áreas de atuação (Lustosa da Costa, 1999a). A experiência foi abandonada depois de 2004. O estado de Santa Catarina começou a desenvolver experiência semelhante a partir de 2003.
} 
Os processos de alargamento das formas de democracia e participação vigentes nas sociedades abertas ensejam o aparecimento de uma pluralidade de atores engajados na formulação de conteúdos, estratégias e práticas de políticas públicas, tornando mais complexos seus processos de formação, para além da lógica sequencial planejamento-execução-avaliação. Diferentes arranjos institucionais engendram cooperação intergovernamental, parcerias público-privadas, mobilização de organizações não governamentais e controle social difuso.

Por outro lado, a complexidade dos problemas que suscitam a intervenção governamental impede que possam ser resolvidos a partir de uma lógica setorial ou mesmo numa única esfera de governo. De fato, a natureza integrada dos problemas, as grandes dimensões territoriais das áreas objeto de intervenção, as diversidades (e desigualdades inter-regionais), as especificidades das clientelas, a heterogeneidade dos grupos interessados e a ineficácia da ação isolada requerem a interveniência de grande número de atores, cada um com seus objetivos específicos e com suas particularidades de organização e funcionamento.

Por isso mesmo, as políticas públicas não são formuladas e, muito menos, implementadas e avaliadas no contexto de uma única organização. Os intrincados processos decisórios em questão dizem respeito a um conjunto de organizações e a um complexo sistema de relações formais e informais que entre elas se estabelece. $\mathrm{O}$ adequado funcionamento dessa rede de atores só é possível quando se adota os princípios da gestão integrada, vale dizer, quando se consegue superar o campo da especialização ou da compartimentalização específica de um único organismo, adotando-se modelos, instrumentos e métodos que se situam nos domínios da interdisciplinaridade e da ação interinstitucional.

A integração ou gestão integrada deve ser buscada como forma de coordenar esforços de diferentes agências públicas, que passam a fazer parte de redes institucionais engajadas na solução de problemas de natureza integrada, nunca resolvidos satisfatoriamente quando examinados a partir de uma perspectiva setorial (Cavalcanti, 1991). A articulação e a coordenação interinstitucional permitem uma utilização integrada da capacidade institucional instalada no setor público nos níveis federal, estadual e municipal, em adequada interação com a iniciativa privada. $\mathrm{Na}$ área da gestão de recursos hídricos, precisamente na gestão das bacias hidrográficas, muito tem sido feito nesse sentido.

A integração macrossetorial implica agrupar as organizações públicas segundo o critério de afinidade de funções. Objetiva conferir maior consistência 
à execução das políticas públicas e dirimir os conflitos decorrentes de uma excessiva setorialização.

A setorialização excessiva fragmenta o Poder Executivo, reduz a eficácia e a efetividade dos programas e projetos de governo, em decorrência da superposição de esforços e do paralelismo de ações, além de diminuir a tempestividade das respostas. A integração remete, portanto, a ideia de melhor coordenação e sinergia no uso dos recursos das diferentes agências governamentais, permitindo também indicar com maior clareza quais são as prioridades e compromissos de governo.

A integração aumenta também a possibilidade de otimizar a alocação dos recursos humanos e financeiros, já que permite que sejam deslocados rapidamente dos setores em que podem estar sendo mal empregados, para outros em que sejam mais necessários ou alcancem maior produtividade.

\section{Flexibilização, universalização, isonomia e equanimidade}

Todas as formas de flexibilização devem ser buscadas para vencer a uniformidade imposta pelas normas universalistas existentes no serviço público, que tendem a tratar de maneira igual situações desiguais e tirar o foco dos objetivos governamentais e organizacionais, gerando processualismo, lentidão e desperdício. É preciso persistir no estudo de formas organizacionais alternativas como as agências autônomas, as organizações militares prestadoras de serviços (OMPS), instituídas no âmbito da Marinha, as organizações sociais, os serviços sociais autônomos e as fundações de direito privado, novos modelos e instrumentos de gestão e formas de contratualização de serviços entre entes governamentais.

Como se viu, o governo americano, por exemplo, criou o mecanismo do waiver, que estabelece a suspensão da vigência de determinadas normas para órgãos que a reivindicam para alcançar maior flexibilidade e cumprir seus objetivos. Trata-se de um instrumento mais eficaz do que a qualificação de agências executivas estabelecida no PDRAE. Entretanto, sempre levando em consideração o contexto brasileiro, a flexibilização deve buscar fugir às tendências ao mimetismo, à uniformidade e à simetria. Ou seja, ao perigo de se copiar modelos nem sempre adequados à nossa ambiência socioeconômica, de desenhar estruturas iguais e paralelas para todas as áreas.

Entretanto, os esforços no sentido de dar autonomia às agências governamentais e a seus dirigentes não podem ir de encontro aos princípios que regem o funcionamento da administração pública. Todos os entes públicos que 
vierem a sofrer transformações com vistas à flexibilização da gestão devem conservar seu compromisso com a universalidade, a isonomia e a equanimidade. Ainda que focada para clientela específica, a ação pública deve ser universal na prestação e equânime no atendimento. Deve assegurar a isonomia no trato com usuários, fornecedores e funcionários. Tratamento igual para situações iguais; tratamento desigual para situações desiguais — tal é o princípio que está na lei, na doutrina e no senso comum.

\section{Gestão pública empreendedora}

A reforma gerencial resgatou os princípios e instrumentos da gestão empresarial, reintroduzindo a administração por objetivos e para resultados e a ideia de responsabilidade pelo cumprimento de metas claras e precisas. No caso brasileiro, deixou de incorporar e pôr em prática os princípios da gestão empreendedora, de sorte a preparar gerentes para o exercício de funções técnicopolíticas. Um modelo ideal supõe a preparação de gerentes capazes de mapear o ambiente, identificar problemas, formular diagnósticos, definir objetivos, decidir em ambiente de incertezas, estabelecer parcerias e alianças, negociar, mobilizar recursos, formar e desenvolver equipes, distribuir autoridade e responsabilidade, dirimir conflitos, controlar e avaliar resultados. Além do mais, a gestão empreendedora supõe que cada gerência é um centro de custos que possui receitas, que deve ampliar; e despesas, que deve realizar com parcimônia.

O recrutamento de profissionais dessa envergadura depende dos critérios de complexos de seleção de candidatos e de um modelo muito versátil e diversificado de capacitação. Além dos necessários conhecimentos, há que incorporar critérios subjetivos relacionados com valores e atitudes, que dependem mais de uma história pregressa do que de pré-disposições para ação. A prova do pudim é sempre ex post factum.

Em todo caso, em trabalho relativamente recente, Bianor Cavalcanti (2005) construiu um modelo de gerência pública em que toma como referência a experiência de grandes administradores para definir o que qualifica como o "gerente equalizador". Trata-se de uma metáfora que toma de empréstimo um conceito da eletrônica e que se refere ao equipamento ou função capaz de equalizar sinais distorcidos que recebe da ambiência para produzir um sinal límpido capaz de ser percebido e entendido por todos. Assim, é o gerente público equalizador, aquele líder capaz de captar, identificar, corrigir, amplificar e devolver os sinais distorcidos que recebe do ambiente da administração pú- 
blica - restrições políticas, jurídicas e orçamentárias — para exercer adequadamente sua liderança e cumprir a missão que lhe foi confiada.

Com esse perfil, o gerente pode firmar um compromisso de gestão, no sentido de conferir orientação finalística à ação gerencial, pois passa a responder por resultados perante a sociedade. Os administradores públicos devem pautar sua conduta não apenas pelos princípios de legalidade, impessoalidade, moralidade, publicidade e eficiência dos atos de gestão, conforme estabeleceu a Constituição de 1988, mas principalmente tendo em vista a responsabilidade objetiva perante a sociedade.

A gestão empreendedora só se tornará possível se a administração pública resgatar também as políticas de capacitação de quadros para o serviço público, formando técnicos e gerentes antenados com o tempo presente, as mudanças sociais e as tecnologias de ponta em matéria de gestão.

\section{Considerações finais}

Uma reforma democrática do Estado deve ter o propósito primeiro de alterar profundamente o padrão de suas relações com a sociedade, de forma a garantir, segundo Wanderley Guilherme (1993), senão o bem-estar, pelo menos o estar dos cidadãos e, secundariamente, superar os dilemas e a crise em que está mergulhado. Trata-se de universalizar o Estado mínimo, quer dizer, instituir um Estado enxuto, forte, porém, na sua competência para impor um padrão de regulação a serviço da democracia, da equidade e do crescimento econômico gerador de oportunidades. Reformar o Estado é fazê-lo afirmar-se como lei universalizante, conferir-lhe poder de polícia e possibilidade de distribuir justiça, mudar as formas de extrair e alocar recursos e aumentar sua capacidade de formular e implementar políticas públicas (Lustosa da Costa e Cavalcanti, 1991).

Intervenções na estrutura do Estado, com o fortalecimento dos instrumentos de formulação e gestão de políticas públicas, notadamente da área social; a elevação dos padrões de desempenho na prestação de serviços públicos; o estabelecimento de formas de cobrança da responsabilidade objetiva dos administradores públicos - accountability, com a redução da impunidade e da corrupção; e a consolidação de uma burocracia profissional, treinada e estável, permitirão a emergência de formas de competição política mais democráticas. Pois, conjugadas com medidas de ordem econômica, essas reformas ensejarão o surgimento de lideranças mais autênticas, o fortalecimento do sistema partidário, o aperfeiçoamento do processo eleitoral, a superação das 
tensões entre Executivo e Legislativo e a renovação das práticas de governo. Finalmente, não se pode esquecer que muitas das reformas sociais que ainda estão por ser feitas dependem muito da capacidade do Estado em extrair recursos da sociedade e de implementar políticas públicas.

Embora se saiba que quanto maior for a intervenção do Estado na implementação de políticas distributivas, ainda que adequadamente regulada e orientada para setores bem específicos, maiores serão os riscos de surgimento de distorções relacionadas com o insulamento burocrático, o rent-seeking e a política populista, a reforma democrática se impõe. Assim, mais uma vez, é um sistema político aberto e inclusivo o que permite a vigência de controles sociais efetivos.

As experiências recentes com o processo de mudanças introduzidas pela Constituição de 1988 e com a reforma gerencialista mostram que essas tensões persistem, que talvez nunca sejam totalmente resolvidas. Mas revelam também que é possível reformar o Estado e transformar a sociedade com democracia, descentralização e participação.

\section{Referências}

ABRUCIO, Fernando Luiz. Os avanços e os dilemas do modelo pós-burocrático: a reforma da administração pública à luz da experiência internacional recente. In: BRESSER PEREIRA, Luiz Carlos; SPINK, Peter. Reforma do Estado e administração pública gerencial. Rio de Janeiro: FGV, 1988.

ALCÂNTARA, Lúcio; LUSTOSA DA COSTA, Frederico. Gestão de saúde pública: alguns desafios propostos pelo SUS. Fortaleza: Stylus Comunicações/Secretaria de Saúde do Estado do Ceará, 1992.

ANDREWS, Cristina W.; KOUZMIN, Alexander. Dando nome à rosa: o discurso da nova administração pública no contexto brasileiro. In: SEMINÁRIO INTERNACIONAL REESTRUTURAÇÃO E REFORMA DO ESTADO: BRASIL E AMÉRICA LATINA NO PROCESSO DE GLOBALIZAÇÃO. Anais... São Paulo, 1998.

ANTUNES, Luís Felipe Colaço. A tutela dos interesses difusos em direito administrativo: para uma legitimação procedimental. Coimbra: Almedina, 1989.

BARZELAY, Michael. La nueva gerencia pública: un ensayo bibliografico para estudiosos latinoamericanos (y otros). Revista del CLAD Reforma y Democracia, n. 19, 2001.

BENTO, Leonardo Valles. Governança e governabilidade na reforma do Estado. Barueri: Manole, 2003. 
BOBBIO, Norberto et al. Dicionário de política. Brasília: UnB, 1995.

. Estado, governo e sociedade: para uma teoria geral da política. Rio de Janeiro: Paz e Terra, 2000.

BRESSER PEREIRA, Luís Carlos. Reforma do Estado para a cidadania: a reforma gerencial brasileira na perspectiva internacional. Brasília: 34, 1998.

. Do Estado patrimonial ao gerencial. In: PINHEIRO, Paulo Sérgio; WILHEIM, Jorge; SACHS, Ignacy. (Orgs.). Brasil: um século de transformações. São Paulo: Companhia das Letras, 2001.

; SPINK, Peter (Orgs.). Reforma do Estado e administração pública gerencial. Rio de Janeiro: FGV,1998.

BRITO, José Wagner Costa. Algumas dúvidas quanto à utilidade do nosso planejamento. Fortaleza: Iplance, 1978.

CASTEL, Robert. La inseguridad sócial. Qué es estar protegido? Buenos Aires: Manantial, 2004.

CASTELLS, Manuel. Hacia el Estado red? Globalización econômica e instituciones políticas em la era de la información. In: SEMINÁRIO INTERNACIONAL SOBRE SOCIEDADE E REFORMA DO ESTADO. Anais... Brasília: Mare, 1998.

CAVALCANTI, Bianor Scelza; LUSTOSA DA COSTA, Frederico. Mudança organizacional no setor público. Revista de Administração Pública, v. 25, n. 1, p. 82-106, 1991.

; OTERO, Roberto Bevilacqua. Novos padrões gerenciais no setor público: medidas do governo americano. Brasília: Enap, 1997.

CUNILL GRAU, Nuria. Participación ciudadana: dilemas y perspectivas para la democratización de los Estados latino-americanos. Caracas: Clad, 1991.

. Repensando lo público a través de la sociedad: nuevas formas de gestión pública y representación social. Caracas: Editorial Nueva Sociedad/Clad, 1997.

. A democratização da administração pública: os mitos a serem vencidos. Cadernos FLEM, n. 8, p. 13-59, 2005.

DAHL, Robert. Poliarquia; participação e oposição. São Paulo: Edusp, 1997.

FITOUSSI, Jean-Paul; ROSANVALLON, Pierre. Les nouvelles âges des inégalités. Paris: Seuil, 1996.

FLEURY, Sonia. Reforma del Estado. Revista de Administração Pública, v. 35, n. 5, p. 7-48, 2001. 
. Democracia, descentralização e desenvolvimento. In: Democracia, descentralização e desenvolvimento: Brasil e Espanha. Rio de Janeiro: FGV, 2006.

FUKUYAMA, Francis. Construção de estados: governo e organização no século XXI. Rio de Janeiro: Rocco, 2004.

GIDDENS, Anthony. A terceira via: reflexões sobre o impasse político atual e o futuro da social-democracia. Rio de Janeiro: Record, 1999.

HARRISON, Lawrence E.; HUNTINGTON, Samuel P. (Orgs.). A cultura importa. Rio de Janeiro: Record, 2002.

HIRSCHMAN, Albert. Saída, voz e lealdade. São Paulo: Perspectiva, 1973.

. As paixões e os interesses. Rio de Janeiro: Paz e Terra, 1979.

KLIKSBERG, Bernardo. A modernização do Estado para o desenvolvimento social: algumas questões-chave. Revista de Administração Pública, v. 30, n. 1, p. 78-90, 1996.

. Seis teses não convencionais sobre participação. Revista de Administração Pública, v. 33, n. 3, p. 7-37, 1999.

. Como reformar o Estado para enfrentar os desafios sociais do terceiro milênio. Revista de Administração Pública, v. 35, n. 2, p. 119-151, 2001.

. Como por em prática a participação? Algumas questões estratégicas. Cadernos FLEM, n. 8, p. 61-97, 2005.

LUSTOSA DA COSTA, Frederico. Estado, reforma do Estado e democracia no Brasil da Nova República. Revista de Administração Pública, v. 32, n. 4, p. 71-82, 1998a.

. A reforma do Estado e as organizações sociais. Programa de Estudos e Pesquisas em Reforma do Estado e Governança. Revista de Administração Pública, v. 32, n. 5, p. 209-213, 1998b.

. Há especificidade na gestão social? In: CONGRESSO INTERNACIONAL DO CLAD SOBRE A REFORMA DE ESTADO E DA ADMINISTRAÇÃO PÚBLICA, 3. Anais... Madri, 1998c.

. Avaliação preliminar da reforma do aparelho do estado do Maranhão. Programa de Estudos e Pesquisas em Reforma do Estado e Governança. Revista de Administração Pública. v. 33, n. 1, p. 157-163, jan./fev., 1999a.

. Reforma do Estado: restrições e escapismos no funcionamento das agências autônomas. Programa de Estudos e Pesquisas em Reforma do Estado e Governança. Revista de Administração Pública, v. 33, n. 2, p. 191-199, 1999 b. 
. Por uma reforma de Estado: estratégias alternativas ao paradigma gerencialista. Programa de Estudos e Pesquisas em Reforma do Estado e Governança. In: Revista de Administração Pública, v. 34, n. 1, p. 267-270, 2000.

. Inovação em administração pública: pesquisa, ensino e ação. Governança \& Desenvolvimento - Conselho Nacional de Secretários de Administração (Consad), v. 1, n. 1, abril 2004.

; PECI, Alketa. Desestatização como estratégia de reforma do Estado: análise preliminar da privatização no Brasil de Nova República. Revista de Administração Pública, v. 33, n. 3, p. 191-207, 1999.

; CUNHA, Augusto Paulo. Avatares da participação induzida na gestão de políticas públicas. In: ENCONTRO DE CIÊNCIAS SOCIAIS DO NORTE E NORDESTE, 22. Anais... Belém, 2004.

; __ . Sete teses equívocas sobre a participação cidadã. In: CONGRESSO NACIONAL DA ADMINISTRAÇÃO PÚBLICA: PROJECTOS DE MUDANÇA, 2. Anais... Lisboa: INA, 2005.

LUSTOSA, Isabel. Brasil pelo método confuso: humor e boemia em Mendes Fradique. Rio de Janeiro: Bertrand Brasil, 1993.

MARE. Plano Diretor da Reforma do Aparelho do Estado. Brasília: Presidência da República/Imprensa Oficial, 1995.

MARSHALL, T. H. Cidadania e classe social. Brasília: Senado Federal, 2002.

MOTTA, Paulo Roberto. Administração para o desenvolvimento: a disciplina em busca da relevância. Revista de Administração Pública, v. 4, n. 2, p. 7-45, 1972.

. Modernização administrativa: propostas alternativas para o Estado latinoamericano. Revista de Administração Pública, v. 21, n. 4, 1987.

MOZZICAFREDDO, Juan. Cidadania e administração em Portugal. In: GOMES, João Salis (Orgs.). Administração e política. Oeiras: Celta, 2001.

NOGUEIRA, Marco Aurélio. As possibilidades da política: ideias para a reforma democrática do Estado. Rio de Janeiro: Paz e Terra, 1998.

. Sociedade civil, entre o político-estatal e o universo gerencial. Revista Brasileira de Ciências Sociais, v. 18, n. 52, p. 185-202, 2003.

O'DONNELL, Guillermo. Democracia delegativa? Novos estudos, São Paulo, Cebrap, p. 25-40, 1991.

. Sobre o Estado, a democratização e alguns problemas conceituais. Novos Estudos, n. 36, p. 123-145, 1993. 
OFFE, Claus. Problemas estruturais do Estado capitalista. Rio de Janeiro: Tempo Brasileiro, 1984.

PAULA, Ana Paula. Por uma nova gestão pública: limites e potencialidades da experiência contemporânea. Rio de Janeiro: FGV, 2005.

PEIXOTO, João Paulo M. Ideologia, pragmatismo e reforma do Estado. In:

Reforma e modernização do Estado. Sobral: UVA, 2000.

PETRUCCI, Vera; SCHWARZ, Letícia (Orgs.). Administração pública gerencial: a reforma de 1995. Brasília: UnB/Enap, 1999.

REZENDE, Flávio da Cunha. Por que falham as reformas administrativas. Rio de Janeiro: FGV, 2004.

RIBEIRO, Sheila Maria Reis. Reforma do Aparelho de Estado no Brasil: uma comparação entre as propostas dos anos 60 e 90. In: CONGRESO DEL CLAD, 7. Anais... Lisboa, 2002.

ROSANVALLON, Pierre . La crise de l'État-providence. Paris: Seuil, 1981.

. L'État em France: de 1789 à nos jours. Paris: Seuil, 1990.

. La nouvelle question sociale. Paris: Seuil, 1995.

SANTOS, Wanderley Guilherme. Kantianas brasileiras. Rio de Janeiro: Paz e Terra, 1984.

. Gênese e apocalipse: elementos para uma teoria da crise institucional latino-amerciana. Novos estudos, n. 20, 1988.

. As razões da desordem. Rio de Janeiro: Rocco, 1993.

. Poliarquia em 3D. Dados, v. 41, n. 2, p. 207-281, 1998. Disponível em:

$<$ www.scielo.br/scielo.php?script $=$ sci_arttext $\&$ pid $=$ S0011-5258199800020000 $1 \& \operatorname{lng}=$ en\&nrm $=$ iso $>$.

SEN, Amartya. Desenvolvimento como liberdade. São Paulo: Companhia das Letras, 2000 .

SFEZ, Lucien. Critique de la décision. 4. ed. Paris: Presses de la Fondation Nationale des Sciences Politiques, 1992.

SOUZA SANTOS, Boaventura de. A reinvenção solidária e participativa do Estado. In: SEMINÁRIO INTERNACIONAL "SOCIEDADE E REFORMA DO ESTADO”. Anais... 1998.

TENÓRIO, Fernando. Um espectro ronda o terceiro setor - o espectro do mercado. Mensagem de gestão social. Ijuí: Unijuí, 2004. 
; SARAVIA, Enrique. Escorços sobre gestão pública e gestão social. In: MARTINS, Paulo Emílio; PIERANTI, Octavio Penna (Orgs.). Estado e gestão pública. Rio de Janeiro: FGV, 2006.

TORRES, Marcelo Douglas de Figueiredo. Estado, democracia e administração pública no Brasil. Rio de Janeiro: FGV, 2004. 